Chirurg 2017·88:536

DOI 10.1007/s00104-017-0447-7

Online publiziert: 17. Mai 2017

๑) Springer Medizin Verlag GmbH 2017

CrossMark

\author{
A. Hellinger ${ }^{1}$ I. Roth ${ }^{1}$ - F. C. Biber ${ }^{1}$ M. Frenken ${ }^{1}$ S. Witzleb ${ }^{1} \cdot$ B. J. Lammers ${ }^{2}$ \\ ${ }^{1}$ Klinik für Allgemein- und Viszeralchirurgie, Klinikum Fulda gAG, Universitätsmedizin Marburg - Campus \\ Fulda, Fulda, Deutschland \\ ${ }^{2}$ Chirurgische Klinik I, Lukaskrankenhaus Neuss, Neuss, Deutschland
}

\title{
Erratum zu: Chirurgische Anatomie der Bauchdecke
}

\section{Erratum zu: \\ Chirurg (2016) 87(9):724-730 \\ DOI 10.1007/s00104-016-0257-3}

Im Originalbeitrag ist die Beschriftung von - Abb. 2 leider fehlerhaft. Bitte entnehmen Sie die korrekte Beschriftung der nachfolgenden Abbildungslegende.

\section{Korrespondenzadresse}

PD Dr. A. Hellinger, FEBS

Klinik für Allgemein- und Viszeralchirurgie,

Klinikum Fulda gAG, Universitätsmedizin

Marburg - Campus Fulda

Pacelliallee 4, 36043 Fulda, Deutschland

a.hellinger@klinikum-fulda.de

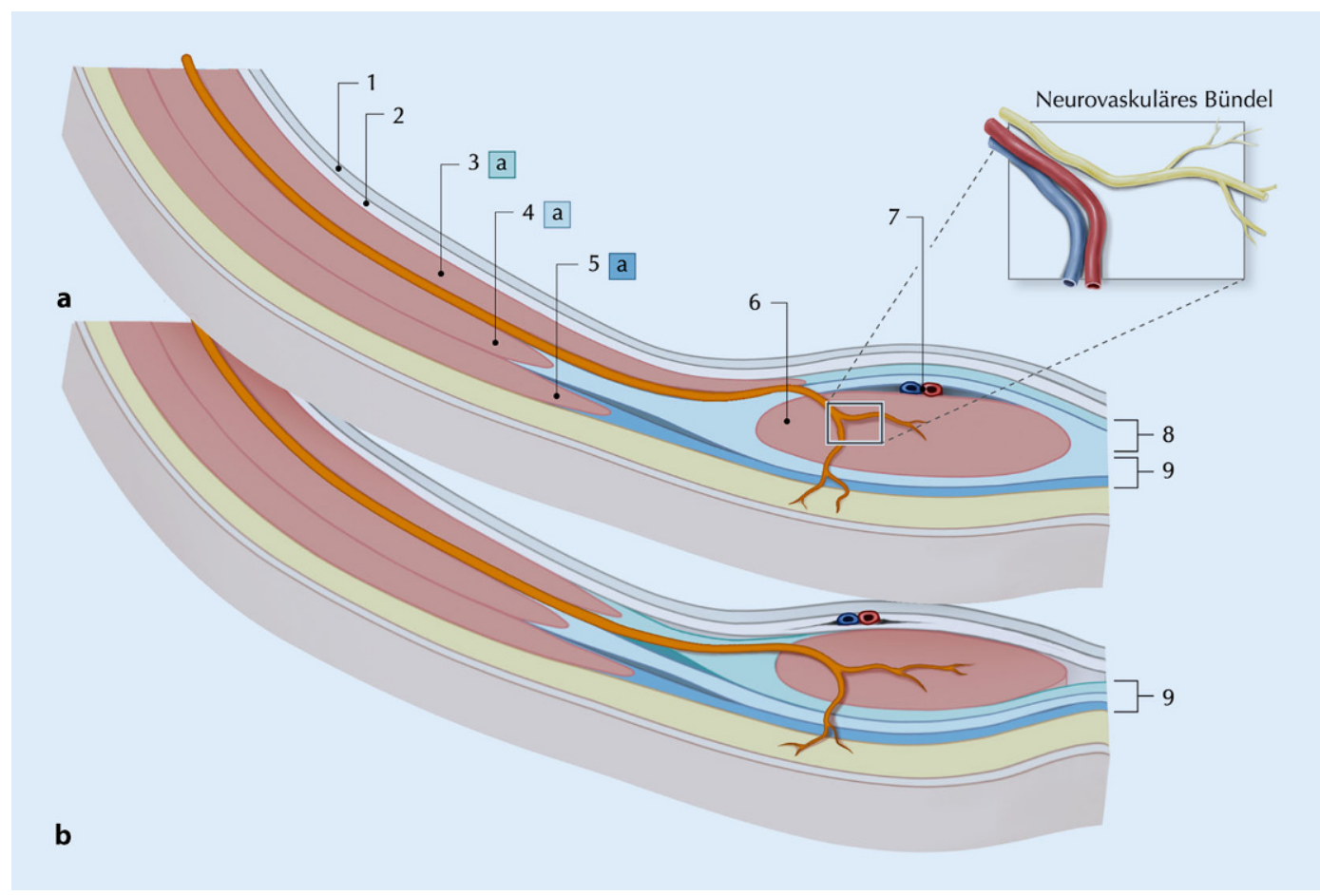

Abb. $2 \triangleleft$ Querschnitt der anterolateralen Bauchwand kranial (a) und kaudal (b) der Linea arcuata: 1 parietales Peritoneum; 2 Fascia transversalis (ventraler und dorsaler Anteil); $3 \mathrm{M}$. transversus abdominis mit Aponeurose $(a)$; $4 \mathrm{M}$. obliquus internus abdominis mit Aponeurose (a); 5 M. obliquus externus abdominis mit Aponeurose $(a) ; 6 \mathrm{M}$. rectus abdominis; 7 A. und V. epigastrica inferior; 8 hintere Rektusscheide; 9 vordere Rektusscheide. (Illustration: E. Gollan, Aachen) 